\title{
Stardom in Multiple Perspectives: What Reality TV Stars Mean for the Star System
}

\author{
Li Cui \\ Southwest University, Chongqing, China
}

\begin{abstract}
This paper attempts to offer a brief review of studies on stardom in recent years. The paper argues that the struggles between ordinariness and extraordinariness, distance and intimacy, active audience and disempowered audience, are all themes of studies on stardom, and the current media context, particularly that of Reality TV, raises new questions on stars from Reality TV. The implications and possible influence of these stars are discussed as well.

Keywords: stardom, Reality TV, popular culture
\end{abstract}

\section{Introduction}

The research on stardom is a growing field, despite its classical roots. Early studies on stars or stardom were those of film studies (Dyer, 1998; Ellis, 1992). The Hollywood film industry and its star system in the 1930s provided earlier star researchers research objects. Although Weber (1978) argued that leadership derived from personal charisma had existed in the human society from the primitive period, stars still are products of modern society, accompanied by the emergence of the mass media, millions of people living in metropolises, and relatively fluid social mobility (Dyer, 1998). Stars might constitute, at least, one of the typical symbols of these consumerist times. Imaging popular culture (movies, soap operas and pop music), without stars could be a dull disaster. Nowadays, with the development of technology and the media industry, particularly Reality TV shows since the 1990s, categories of stars have been broadened to such a degree that researchers need do their work in this field with a more open view than they had 10 years ago (Redmond \& Holmes, 2007).

The omnipresence of stars does not mean that the study in this field will be easy. It is easier to ensure the hierarchical order among stars, celebrities and idols than to conceptualize stars. In other words, the question of the hierarchical order of these terms should be clarified, at least in this study. Redmond and Holmes (2007) cite the work of Marshall (1997) and argue that the concept of "star" is above that of "celebrity". This ordering is also taken up in this study. In addition, in this study, generally, the term "star" will represent a higher position than that of "idol" and "celebrity".

\section{Definitions on "Star"}

There is no such a thing as a clearly defined concept of "star" or "stardom" (Tolson, 1996), to differentiate "stars" from "celebrities” or "idols". Even though the term "star" is far from stable (Tolson, 1996), scholars still make efforts to define it, such as Wernick (1991) and Ellis (1992) have done. Both Wernick (1991) and Ellis

Li Cui, Ph.D, Associate Professor, School of Journalism and Communication, Southwest University, China.

Correspondence concerning this article should be addressed to School of Journalism and Communication, Southwest University, Chongqing, Beibei, China. E-mail: cloudhk22@gmail.com. 
(1992) reveal one significant characteristic of stars-their images, in their performances on screen, but not limited to these, which make them be able to enter into circulation as commodities. Wernick's definition (1991) indicates that a "star" is anyone whose name and fame have been built up to the point where reference to them, via mention, mediatized representation or live appearance, can serve as a promotional booster in itself. (p.106)

This concept is helpful for people to establish one general characteristic of the essence of stars-they are profitable products. For what people want, however, this is not enough at all. This study prefers to define "stars" loosely, as Ellis (1992) has defined, which provides the space for exploration and clarification of characteristics. Ellis (1992) considers that "the star is at once ordinary and extraordinary, available for desire and unattainable" (p.91).

It is better to understand the stars or stardom according to the way in which scholars' views are considered, rather than attempt concrete definitions. Although stars, as mentioned before, are considered above celebrities in this study, it still works that the conclusions of diverse research studies on celebrities might be applied to the study of stars. Turner (2004) concluded that celebrities could be seen as products of cultural process, commodities, or even social relations. Each of these angles separately represents a research direction, from cultural studies to political economy, in this field. Some works on stars can be considered in this way. One representative trend tends to regard stars as half-open texts, in which meaning is constructed by the audience (Dyer, 1998; Ellis, 1992; Zhang \& Hu, 2011). Dyer’s work explored the polysemy of stars' images and revealed that the meanings of stars are linked to audience interpretation and their social condition rather than fix to the performance or images of stars on screen or in magazines (1998). Another trend is to view stars as commodities or even industries (Gamson, 1994; Gamson, 2001; Chen, 2007). For example, in china, film stars in contemporary films are always viewed as signs of consuming (Chen, 2007). Following this perspective, the production and consumption of stars should be examined at the same time as the political economy background behind stars, particularly in the culture industry, as the latter exerts an important impact on the manufacture of the meaning of stars (Gamson, 1994). The third trend is to treat stars as a media process or "cultural formation" (Turner, 2004), which tends to view stars as products of a series of media activities and interpretations of audiences. With the third trend, some cultural study works have attempted to understand stars and celebrities according to the viewpoint of media power. In these works, stars are seen as concentrations of media's symbolic power, with the point lying in the naturalized hierarchical order encompassing both audience and stars (Litter, 2004; Couldry, 2000). This study basically takes the last perspective. This does not mean, however, that other perspectives are invalid, or that they will not be referred to in this study.

\section{Ordinariness and Extraordinariness}

Turning the question of "what" into the question of "why", people will find that the exploration of "star quality" occupies most of the relevant coverage of the issue. For researchers, the question of why stars are stars can inspire particular academic interest. The reason partly lies in that the hierarchic division between audience and stars, if taken as an assumption, is generated from the stars' quality, which is supposedly unattainable for ordinary people. As Dyer mentioned (1998), the construction of stardom should be explored in cultural and historical context. Yet, no matter the historical context or cultural context in which the question is put, one duality exists in the exploration—ordinariness, and specialness or extraordinariness—all the time (Ellis, 1992; Dyer, 1998; Litter, 2004). Ordinariness and extraordinariness are contradictive, and yet co-exist in the construction of stardom (Dyer, 1998; Ellis, 1992; Darling-wolf, 2004). The emphasis on ordinariness or 
specialness actually refers to the struggle between the idea that the stars are "magic", and the idea that they are "natural". The former implies the possibility that everyone can become a star, and that the hierarchical boundary between audience and stars is open to being bypassed; while the latter, opposite to the former, means the resources are unattainable for everyone, and only those with talent or specialness deserve the fruit of fame.

Diverse historical contexts, star types, and program genres decide the different proportion of extraordinariness and ordinariness in the formula of stardom. In primitive society, charisma mainly derived from specialness, such as, psychic or spiritual specialness, which is not attainable for everyone (Weber, 1978). Only from this "supernatural" specialness and the symbolic power derived from it, is the domination within a community natural and acceptable. What Weber talked about was not the "star" as people explore here, although his classic works opened the research direction for later scholars. When Dyer (1998) discussed stars of the 1920s and 1930s, the co-existence of the ordinariness and extraordinariness was mentioned, but he argued that construction of stardom was mainly dependent on the specialness, which separated stars from ordinary people and made them unique. In the 1930s, stars rose because of the discovery of their talents or star quality (Gamson, 1994). The coverage of stars' ordinariness, such as, their personality or ordinary moments in their lives, is just an accessory to their stardom (Dyer, 1998). This point also is admitted in other works (Ellis, 1992). Among these works on film stars, the focus is so obvious that television personalities were not even recognized as stars, since their on-stage performances are closed to audiences, and too ordinary (Ellis, 1992).

With the development of media industry and technology, such as, the amplification of Reality TV, the media context is different from that of 20 years ago. There are a number of new-type stars, or celebrities, jumping on screen or into the headers of newspaper articles. Their existence has raised the old question of the ordinariness and extraordinariness again, but new ideas might be necessary to answer them. Reality TV is more likely to construct stardom for its contestants-ordinary people, mostly-by emphasizing their realness and ordinariness (Holmes, 2004; Reijnders, Rooijakkers \& Zoonen, 2007). Different from the ordinariness of stars' images in the 1930s, when it was an accessory, now ordinariness has become a main booster for stardom, such as that created through Reality TV (Turner, 2006). Some stars and celebrities, from pop idols and soap operas, and even from talk shows, are well-known simply because of their media exposure rather than their talent or greatness (Holmes, 2004).

Taking talent shows as an example, the general process of production of stars includes three elements: discovering of ordinary people, then separating them from ordinary life, and finally processing them for stardom (Turner, 2006, p.154). Besides the emphasis on ordinariness, the original part of this process is the emphasis on the production process of stardom for the audience, which brings about closeness and intimacy between audience and contestants, the would-be stars (Holmes, 2004). Actually, media has attempted to construct this kind of intimacy since the 1950s (Gamson, 1994); however, the increasingly importance of it in program genres has drawn audience attention since the 1990s. Visibility of the production process of stars was thought to be a threat for the construction of stardom, because it destroys the fantasy of fans (Ellis, 1992), and threatens the idea that fame is natural too (Gamson, 2001). This is why this kind of intimacy had not been welcome for media industry participants previously (Gamson, 1994).

\section{Reality TV Stars: Rise of Ordinariness and Intimacy?}

There are optimistic opinions that the rising importance of ordinariness and intimacy in Reality TV or other genres might imply the deconstruction of traditional stardom, and even the democratization of fame 
(Gamson, 2001). Gamson (2001) mentions that the invitation of ordinary people to enter into the production process of stardom might eliminate the gap between audience and celebrities, and empower the former in the process of shaping stars. However, there are other opinions that this intimacy with the production process does not mean the "democratic turn" of stardom (Turner, 2006; Turner, 2004; Holmes, 2004). Instead, the production process of stardom in shows emphasizes the transformation from the ordinary to stars (Reijnders, Rooijakkers., \& Zoonen, 2007), or, in other words, the offer of "elevated heights of fame” (Holmes, 2004, p.153). The changes are celebrated, and the hierarchic boundary between ordinary people and stars or celebrities is still reinforced (Cui \& Lee, 2010; Reijnders, Rooijakkers., \& Zoonen, 2007). Besides, whether stardom in these genres can last for a long time is still open to question. For this kind of celebrity or star, some argue, from empirical evidence, the star status is too dependent on the platform that produces him to be long-term (Turner, 2004). Further, Turner (2006) considers that such stars or celebrities, particularly those from Reality TV and soap operas, are replaceable commodities who rise quickly and soon disappear. This implies that the possible negotiation of media power in the production of these stars from Reality TV might influence the reception of the stardom of these stars. However, the question is still waiting for more theoretical and empirical evidence to clarify.

\section{Active Audience and Disempowered Audience}

Concerning the role of the audience in the production and reception of stars, there are two contrary views. From the perspective of media power, the stars are concentrations of symbolic power which imply the disempowerment of the audience (Litter, 2004). Thus the fight for stardom is the process of being against the “disempowerment of "the ordinary" (Litter, 2004, p.10). Further, Couldry (2000) has argued that the audience's viewing of stars in studio tours is even a part of the construction of the symbolic boundary between the media world and ordinary world. This viewpoint is different from that of active audience participation in stardom studies, such as that of Dyer (1998). There is the third view, however-that, while the audience might be empowered at the beginning of talent shows (group-audition, voting, etc.), but they gradually lose their power with the development of the show under the manipulation of the media (Cui \& Lee, 2010). By the end of talent shows, the media had reproduced their authority and turned the audience into, even though implicitly, supporters of the media/ordinary boundary (Cui \& Lee, 2010), which means that the "empowered" audience has been transformed into a "disempowered" one, finally; and that all of this is just a media process (Couldry, 2000).

A special group of a star's audience becomes his/her fans. The traditional fandom studies mostly keep to a model of a text that is open and polysemic, which provides many possibilities for interpretation, as the audience may interpret the text in diverse ways, some obsessive audience members being the fans (Pullen, 2004). Within this frame, the fans are always viewed as a deviant, more or less, audience, as they constitute a special group addicted to some texts (Pullen, 2004; Grossberg, 1992). For example, fans may tend to be accomplished at consuming some texts, stars or films, in order to construct their own identities, gender or morality (Einerson, 1998; Darling-Wolf, 2004). This approach ignores not only the agency of fans, but also the working system of fans getting pleasure from their consuming. For instance, they always emphasize how fans use texts to do something, as gender identity construction (Darling-Wolf, 2004), rather than what fans could do for texts.

Different from this approach, Fiske and some scholars contend that fans are active consumers more than they are an obsessive audience (Fiske, 1992; Grossberg, 1992). On one side, their consumption is not blind, and 
it more and more attains the attention of the entertainment industry (Pullen, 2004). On the other side, their consuming, even just as a symbol of consumerism and individualism, still may have some democratic implications for people in some special media contexts, such as that of China (Fung, 2009).

According to this view, fans are actively involved in cultural production and stardom (Fiske, 1992; Grossberg, 1992; Pullen, 2004). Particularly in these internet times, the booming of online fan communities spurs this phenomenon (Pullen, 2004), which tends gradually to rule out the boundaries of race or nationality (Pullen, 2004; Darling-Wolf, 2004). Grossberg (1992) suggests that fans have the power to construct authority in consuming cultural products - they can make things matter, and can promote this authority to other audiences (Grossberg, 1992), which is crucial for the production of stars. Fans thus take part in the creation of stars, particularly of stars from talent shows, to some degree. For example, some fans of Super Girls' Voice (SGV) in 2005 attempted to call for votes for their favorite contestants and made those girls into stars, even by methods, such as campaigning for them (Keane, Fung, \& Moran, 2007).

There are diverse opinions on the political potential of fans. For some scholars, fan organizations have political potential (Zoonen, 2009; Fung, 2009), while for others, fans are seen as always negotiating with the mediated reality, and their potential should be evaluated carefully (Jones, 2003). At any rate, one thing is hard to deny: The participation of fans of talent shows overpasses that of other fans of other television formats, so that they have even created a new fan culture (Keane, Fung, \& Moran, 2007). Thus it might be a good time to evaluate the effect of fandom on stardom rather than to focus on the influence of stars on fans. The analysis of the fans of Super Girls provides a useful reference for the examination of this issue (Keane, Fung, \& Moran, 2007). All these considerations inform people that audience's power in the production of stardom should be evaluated according to an alternative frame, which considers the contribution of audience activities to the stardom of talent stars.

\section{Conclusion}

In conclusion, the struggles between ordinariness and extraordinariness, distance and intimacy, active audience and disempowered audience, are all themes of studies on stardom, and the current media context, particularly that of Reality TV, raises new questions. For instance, Reality TV, particularly talent shows, raises disputes on the stardom of stars from Reality TV. One of their focuses is that whether the possible negotiation of media power in the production of these stars influences the reception of these stars. There are optimistic opinions that the rising importance of ordinariness and intimacy in Reality TV might imply the deconstruction of traditional stardom, and even the democratization of fame (Gamson, 2001). However, other scholars contend that the production process of stardom in talent shows emphasizes the transformation from the ordinary to stars (Reijnders, Rooijakkers, \& Zoonen, 2007), and the hierarchic boundary between ordinary people and stars or celebrities is still reinforced (Cui \& Lee, 2010; Reijnders, Rooijakkers, \& Zoonen, 2007). No matter their opinions are, one undeniable fact is that stars from Reality TV have entered in stardom studies and exerted influences on star system and popular culture. In so far as questions on their star quality or reception, people are still waiting for theoretical and empirical explorations to clarify.

\section{References}

Cai, Q., \& Xie, X. L. (2006). Zhongxing shishang: Dianshi shifang de meiti shenhua. [The androgynous fashion: a media myth set by the television]. Chuanmei Xueshuwang. Retrieve from http://academic.mediachina.net/academic_xsjd_view.jsp?id=4985 
Chen, X. Y. (2007). Dianying mingxing, shijue zhengzhi yu xiaofei wenhua. [Film stars, visual politics and consumer culture: The Chinese film-stars in the context of contemporary urban China]. Wenyi Yanjiu, 1, 12-18.

Couldry, N. (2000). The place of media power: pilgrims and witnesses of the media age. London, New York: Routledge.

Couldry, N., \& Markham, T. (2008). Troubled closeness or satisfied distance? Researching media consumption and public orientation. Media, Culture \& Society, 30(1), 5-21.

Cui, L., \& Lee, F. L. F. (2010). Becoming extra-ordinary: Negotiation of media power in the case of Super Girls' Voice in China. Popular Communication: The International Journal of Media and Culture, 8(4), 256-272.

Darling-wolf, F. (2004). Vitually multicultural: Trans-Asian identity and gender in an international fan community of a Japanese star. New Media Society, 6, 507-528.

Darling-Wolf, F. (2004). Virtually multicultural: Trans-Asian identity and gender in an international fan community of a Japanese Star. New Media Society, 6(4), 507-528.

Dyer, R. (1998). Stars. London: BFI Pub.

Ellis, J. (1992). Visible fictions: cinema, television, video. London, New York: Routledge.

Einerson, M. J. (1998). Fame, fortune, and failure: Young girls’ moral language surrounding popular culture. Youth \& Society, 3 (2), 241-257.

Fiske, J. (1992). The cultural economy of fandom. Lisa A. Lewis. (Ed.), The Adoring audience: Fan culture and popular media. (pp.30-50). London, New York: Routledge.

Fung, A. Y. H. (2009). Fandom, youth and consumption in China. European Journal of Cultural Studies, 12(3), 285-303.

Gamson, J. (1994). Claims to fame: celebrity in contemporary America. Berkeley: University of California Press.

Gamson, J. (2001). The assembly line of greatness: celebrity in $20^{\text {th }}$ century America. C. L. Harrington., \& D. D. Bielby. (Eds.), Popular culture: production and consumption. (pp. 259-282). Malden, Mass, Oxford: Blackwell Publishers.

Grossberg, L. (1992). Is there a fan in the house? The affective sensibility of fandom. L. A. Lewis. (Ed.), The Adoring audience: Fan culture and popular media. (pp. 50-69). London, New York : Routledge.

Holmes, S. (2004). Reality Goes Pop! Reality TV, popular music, and narratives of stardom in Pop Idol. Television \& New Media, 5(2), 147-172.

Jones, J. M. (2003). Show your real face: A fan study of the UK Big Brothers transmissions. Investigating the boundaries between notions of consumers and producers of factual television. New Media \& Society, 5(3), 400-421.

Keane, M., Fung, A.Y. H., \& Moran, A. (2007). New Television, Globalization, and the East Asian Cultural Imagination. Hong Kong: Hong Kong University Press.

Litter, J. (2004). Making fame ordinary: intimacy, reflexivity, and “keep it real”. Mediactive: Ideas/Knowledge/Culture, 2, 8-25.

Redmond, S., \& Holmes, S. (2007). Stardom and celebrity: A reader. S. Redmond., \& S. Holmes (Eds.), (pp. 1-11). London: SAGE Pub.

Pullen, K. (2004). Everybody’s gotta love somebody, sometime: Online fan community. Web Studies. (2nd ed.). D. Gauntlett., \& R. Horsley. (Eds.), (pp. 80-91). New York: Distributed in the United States of America by Oxford University Press.

Reijnders, S. L., Rooijakkers, G., \& Zoonen, L. V. (2007). Community spirit and competition in Idols—Ritual meanings of a TV talent quest. European Journal of Communication, 2007, 22(3), 275-292.

Rojek,C. (2001). Celebrity. London: Reaktio Books.

Tolson, A. (1996). Mediation: text and discourse in media studies. London, New York: Arnold.

Turner, G. (2004). Understanding celebrity. London: SAGE.

Turner, G. (2006). The Mass production of celebrity: “Celetoids”, reality TV and the "demotic turn”. International Journal of Cultural Studies, 9(2), 153-165.

Weber, M. (1978). Economy and society: An outline of interpretive sociology. Guenther Roth., \& Claus Wittich. (Eds.), Berkeley: University of California Press.

Wernick, A. (1991). Promotional culture: advertising, ideology and symbolic expression. London: Sage.

Zhang, Y. J., \& Hu, M. N. (2011). Zhongguo dianying mingxing yanjiu. [Study of film stars in China]. Dianying Yishu, 336, 105 -108 .

Zoone, L.V. (2009). Imagining the fan democray. European Journal of Communication, 19(1), 39-52. 